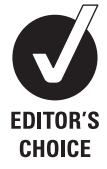

See Editorial, p 159

${ }^{1}$ Rheumatology Division, Universidade Federal de Sao Paulo, Sao Paulo, Brazil 2Pneumology Division, Universidade Federal de Sao Paulo, Sao Paulo, Brazil

Correspondence to Professor Dr Jamil Natour, Universidade Federal de Sao Paulo, Rua Botucatu 740, São Paulo 04023-900, Brazil; jnatour@unifesp.br

Received 25 July 2010 Accepted 21 October 2011 Published Online First 29 November 2011

\title{
Impact of cane use on pain, function, general health and energy expenditure during gait in patients with knee osteoarthritis: a randomised controlled trial
}

\author{
A Jones, ${ }^{1}$ P G Silva, ${ }^{1}$ A C Silva, ${ }^{1}$ M Colucci, ${ }^{2}$ A Tuffanin, ${ }^{2}$ J R Jardim, ${ }^{2}$ J Natour ${ }^{1}$
}

\begin{abstract}
Objective To assess the impact of daily cane use during gait in relation to pain, function, general health and energy expenditure among patients with knee osteoarthritis.
\end{abstract}

Method Sixty-four patients were randomly assigned to an experimental group (EG) or control group (CG). The EG used a cane every day for 2 months, whereas the CG did not use a cane in this period. The first outcome was pain and the second were function (Lequesne and WOMAC), general health (SF-36) and energy expenditure (gas analysis during the 6-minute walk test (6MWT) with and without a cane). Evaluations were performed at baseline, 30 and 60 days.

Results The groups were homogeneous for all parameters at baseline. Compared with the CG, the EG significantly improved pain (ES 0.18), function Lequesne (ES 0.13), some domains of SF-36 (role physical, ES 0.07 and bodily pain, ES 0.08 ) and distance on the 6MWT with the cane (ES 0.16). At the end of the 6MWT with the cane, the EG significantly improved energy expenditure (ES 0.21), carbon dioxide production (ES 0.12) and metabolic equivalents (ES 0.15) compared with the CG.

Conclusion A cane can be used to diminish pain, improve function and some aspects of quality of life in patients with knee osteoarthritis. The prescription of a cane should take into account the substantial increase in energy expenditure in the first month of use, whereas energy expenditure is no longer a factor for concern by the end of the second month due to adaptation to cane use.

The trial was registered in clinicaltrials.gov (NCT00698412).

Osteoarthritis is one of the most common joint diseases worldwide and is characterised by the progressive degeneration of joint cartilage and decreased regeneration. ${ }^{1-3}$ osteoarthritis is a highly prevalent disease, with a low incidence before the age of 40 years, but progressively increasing thereafter. ${ }^{1-3}$ The prevalence of osteoarthritis is higher among women over the age of 50 years. ${ }^{14}$ Joint damage from osteoarthritis progresses slowly and leads to joint stiffness, progressive deformity, joint instability and loss of function, thereby affecting general health. ${ }^{5-7}$

Any disease in the knee can adversely affect gait, leading to reduced gait speed. ${ }^{8}$ Muscle weakness, pain, joint deformity and instability in patients with knee osteoarthritis increase energy expenditure during gait. ${ }^{9}$ Patients with knee osteoarthritis generally shift their weight nearly completely to the medial compartment during gait. ${ }^{10}$ Therefore, decreasing the load on the medial compartment should be one of the treatment objectives for such patients. ${ }^{11} 12$ The use of a cane with the purpose of reducing the biomechanical load on the joints of the lower limb is part of the treatment for patients with knee osteoarthritis. This strategy is expected to increase both independence and tolerance to exercise, allowing a more efficient gait, with a reduction in joint stress. ${ }^{12-15}$ A recent study assessing moments of knee strength with contralateral and ipsilateral cane use in patients with knee osteoarthritis demonstrated that contralateral cane use is more appropriate for such patients, as it is associated with lower peak force on the knee, thereby reducing the load on the medial compartment. ${ }^{11} 16$ Contralateral cane use also allows the affected lower limb to advance together with the upper limb carrying the cane, following a normal gait pattern, with pelvic rotation matched by a counter rotation of the trunk and shoulder. ${ }^{12}$

Although most guidelines for the treatment of knee osteoarthritis recommend cane use, ${ }^{17-19}$ no studies assessing its effectiveness were found. Therefore, the aim of the present study was primarily to assess the impact of daily cane use during gait in relation to pain, and secondarily the impact on function, general health and energy expenditure among patients with knee osteoarthritis.

\section{METHODS}

\section{Study design and patients}

A single-blind parallel group randomised controlled trial was carried out with a 2-month follow-up period. Sixty-four patients were selected from the rheumatology outpatient clinic. Inclusion criteria were: diagnosis of knee osteoarthritis based on the criteria of the American College of Rheumatology; ${ }^{20}$ visual analogue scale (VAS) for knee pain score ranging from 3 to 7 (maximum 10); stable doses of antiinflammatory drugs; and no regular physical exercise in the month before the study. Exclusion criteria were: symptomatic heart disease; symptomatic disease of the lower limbs (other than knee osteoarthritis) or upper limb that would secure the cane; symptomatic lung disease; severe systemic disease; severe psychiatric illness; regular physical exercise 
(three or more times per week for at least 3 months); drug injection in the knee in the previous 3 months; physiotherapy on the lower limbs in the previous 6 months; cane use in the previous 3 months; inability to walk and geographical inaccessibility.

This study received approval from the ethics committee of the university and all patients signed a term of informed consent. A computer-generated randomisation list with a 1:1 ratio (created by a statistician not involved in the trial) was used to allocate patients randomly to the experimental group (EG) and the control group (CG). Concealed randomisation was performed with opaque sealed envelopes and an independent researcher not involved in eligibility assessment, outcome assessment, or treatment kept the concealed assignment scheme in a locked cupboard in a central location. Allocation was revealed to the treating physiotherapist after the baseline evaluation.

This trial was registered in clinicaltrials.gov (NCT00698412) and this manuscript was prepared following the CONSORT statement

\section{Intervention}

Wooden canes with a T-shaped handle were used. All patients were positioned standing comfortably erect, with arms relaxed alongside the body and wearing shoes with low heels. The cane was placed with the tip on the floor, $10 \mathrm{~cm}$ from the lateral margin of the ankle (towards the metatarsus) and a mark was made at the height of the distal fold of the wrist. ${ }^{21} 22$ After cutting the cane to the proper height, the elbow flexion angle was measured, which should be between $20^{\circ}$ and $30^{\circ}$; if this angle was not achieved, the cane was adjusted until it reached the proper elbow flexion angle. The canes for the CG were locked in a cabinet by the primary researcher.

The EG took the cane home for day-to-day use for 2 months, whereas the participants in the CG were instructed to maintain their normal lives and did not use any auxiliary gait devices for 2 months. The individuals in the CG maintained their usual treatment for knee osteoarthritis and received their canes at the end of the study to begin day-to-day use.

On the first evaluation, a physiotherapist offered a 5-min training period to each patient for instructions on using the cane on the contralateral side and setting the tip of the cane on the ground alongside the more symptomatic knee during the stance phase. During this training session, the patient walked along the same path determined for the subsequent walk test.

\section{Clinical evaluations}

Evaluations were carried out by a blinded assessor at baseline (T0), 30 (T30) and 60 (T60) days. The following demographic and clinical information were collected at baseline: radiological degree of osteoarthritis, dominant side, affected side, presence of pain, duration of osteoarthritis, weight and height.

Data were collected in the rheumatology outpatient clinic. The following outcomes were measured:

- Primary outcome:

$\triangleright$ Pain-measured using a VAS ranging from $0 \mathrm{~cm}$ (no pain) to $10 \mathrm{~cm}$ (unbearable pain); ${ }^{23}$

- Secondary outcomes:

$\triangleright$ Function-measured using the Lequesne knee questionnaire, ${ }^{24}$ with scores ranging from 0 to 24 points (lower scores denote better function), the Western Ontario and McMaster Universities (WOMAC) questionnaire), ${ }^{25}$ with overall scores ranging from 0 to 96 points (lower scores denote better function); $\triangleright$ General health-assessed using the short form 36 (SF-36) questionnaire, ${ }^{26}$ with overall scores ranging from 0 to 100 (higher scores denote better general health);

$\triangleright$ Energy expenditure-the subjects performed the 6-minute walk test (6MWT) in compliance with the American Thoracic Society guidelines, ${ }^{27}$ using a portable metabolic system (model K4b2, COSMED - Cardio Pulmonary Diagnostic, Rome, Italy) consisting of a portable unit (dimensions $170 \times 55 \times 100 \mathrm{~mm}$; weight $475 \mathrm{~g}$ ) and battery (dimensions $170 \times 48 \times 90 \mathrm{~mm}$; weight $400 \mathrm{~g}$ ). This system is worn on the chest using a harness that fits over both shoulders and around the waist, with the portable unit in the front pocket and battery in the back pocket. A flexible rubber facemask (Hans-Rudolph, Kansas City, Missouri, USA) is placed over the participant's mouth and nose, secured by a mesh head cap and four clips. To avoid a learning effect, the test was carried out twice with the cane and twice without the cane ${ }^{28}$ on two separate days; the patient first performed two tests under one condition and the other condition was performed within a 7-day period, with at least one non-test day between tests. The order for the tests was determined randomly on the first day. Between tests performed on the same day, the patient was instructed to rest in a sitting position for at least 30 min or until respiratory and heart rate parameters returned to baseline values. The longer distance travelled on the 6MWT with and without cane use was used for analysis. Respiratory and metabolic parameters were assessed breath by breath. Before and after the 6MWT, heart rate response was measured using a heart monitor and knee pain experienced during the test was determined using the Borg scale, ${ }^{29}$ which was administered before and after the 6MWT;

$\triangleright$ Cane use-patients in the EG received a chart on which they registered mean daily cane use;

$\triangleright$ Consumption of non-steroidal anti-inflammatory drugs (NSAID) - the patients were instructed to take sodium diclofenac (50 mg) every $8 \mathrm{~h}$ whenever they experienced pain equal to or above 7 on the VAS; patients could suspend use of the medication when the pain reached 5 on the scale (this was carried out based on the patient's judgement). All patients received a chart to record the amount of NSAID drugs taken daily.

\section{Statistical analysis}

Sample size was calculated for repeated-measure analysis of variance (ANOVA) with two repetitions per situation, using the VAS for pain as the main parameter, with a SD of $2 \mathrm{~cm} .{ }^{18}$ For the determination of a minimal effect of $2 \mathrm{~cm}$, a $5 \% \alpha$ error, $20 \% \beta$ error and SD $(\sigma)$ of $2 \mathrm{~cm}$ were established, using the formula described by Filho. ${ }^{30}$ The calculation determined a minimal sample of 27 patients per group. Considering a possible loss of $20 \%$, it was determined that each group would comprise 32 patients.

The following tests were used:

- $\chi^{2}$, Student's t test and Mann-Whitney-to determine the homogeneity of the sample at the initial evaluation;

- Repeated-measures ANOVA with Bonferroni adjustments-to determine differences in the outcomes between groups over time;

- Effect size ( $\omega$ squared) and 95\% CI-calculated for the parameters with statistically significant differences between groups over time (ANOVA). The $\omega$ squared is an effect size measure associated with ANOVA. It is an overall estimate 


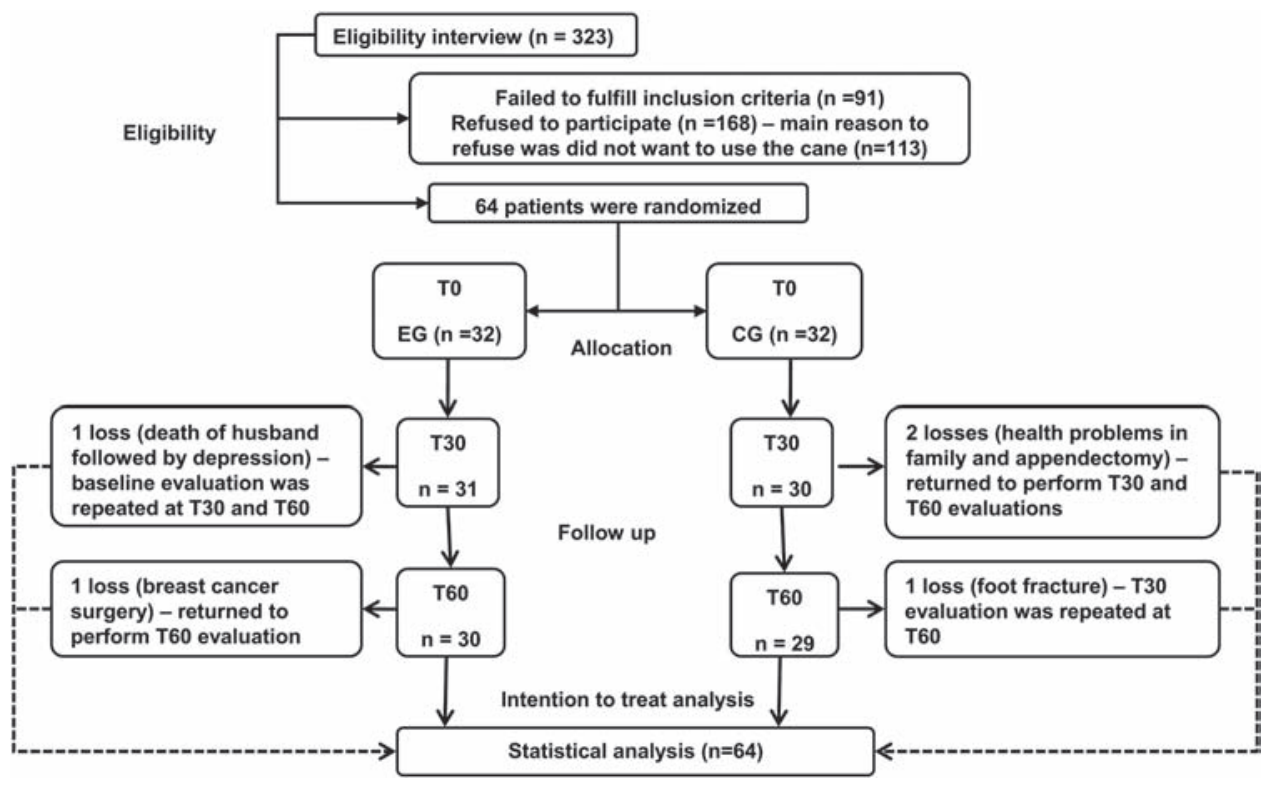

Figure 1 Flowchart of the study. CG, control group; EG, experimental group; T0, baseline; T30, evaluation after 30 days; T60, evaluation after 60 days.

for both follow-up points and the interpretation is small 0.01, medium 0.06 and large $0.14 ; 1$

- Paired Student's t test-intragroup analysis was performed for the parameters measured during the 6MWT with and without cane use for the determination of differences within each group.

Using intention-to-treat analysis, the data from all patients initially enrolled were analysed. For cases in which there was interruption of treatment, the patients were first asked to come in and only perform the evaluations. For patients who refused to return for the evaluations, the last data collected were repeated in the subsequent evaluations.

\section{RESULTS}

The data were collected between 2007 and 2009. Three hundred and twenty-three patients with knee osteoarthritis were interviewed individually until finding 64 patients who satisfied the inclusion criteria. These patients were randomly allocated to the two groups (experimental and control) immediately following the first evaluation. Figure 1 displays a flowchart of the study. The main reason why patients refused to participate in the study was because they did not want to use a cane $(\mathrm{n}=113)$.

At baseline, no statistically significant differences were found between groups regarding demographic and clinical characteristics (table 1) or the parameters assessed on the 6MWT with and without cane use (table 3). Eighty-nine per cent of the patients were women and $11 \%$ were men; $79 \%$ were right-handed; $62 \%$ had osteoarthritis in the right knee and 38\% had osteoarthritis in the left knee; $53 \%$ had grade II osteoarthritis and $47 \%$ had grade III.

\section{Comparisons between groups over time}

The EG exhibited statistically significant improvements over time in comparison with the CG with regard to pain measured by VAS with $\mathrm{p}<0.001$ (figure 2) and SF-36 bodily pain domain $(p<0.001)$ and function measured by the Lequesne knee questionnaire $(\mathrm{p}=0.001)$ and SF-36 physical function domain $(p<0.001)$. No statistically significant differences between
Table 1 Demographic and clinical characteristics at baseline

\begin{tabular}{lccl}
\hline & CG & EG & p Value \\
\hline Age (years) & $62.56(5.88)$ & $61.75(5.92)$ & 0.899 \\
Disease duration (years) & $6.53(3.87)$ & $6.06(2.82)$ & 0.581 \\
Height (cm) & $1.56(0.63)$ & $1.58(0.66)$ & 0.253 \\
Weight $(\mathrm{kg})$ & $72.34(9.09)$ & $72.50(7.55)$ & 0.941 \\
BMl $\left(\mathrm{kg} / \mathrm{m}^{2}\right)$ & $29.54(3.42)$ & $29.01(2.83)$ & 0.200 \\
VAS for pain (range 0-10 cm) & $5.48(1.23)$ & $5.63(1.02)$ & 0.619 \\
Lequesne (0-24) & $14.59(3.6)$ & $15.7(3.3)$ & 0.198 \\
WOMAC (0-96) & $47.69(14.7)$ & $54.1(14.2)$ & 0.111 \\
SF-36 (0-100) & & & \\
$\quad$ Physical functioning & $28.9(13.0)$ & $35.9(17.5)$ & 0.127 \\
Role physical & $22.7(24.07)$ & $23.4(31.7)$ & 0.912 \\
Bodily pain & $46.1(15.3)$ & $48.7(15.1)$ & 0.571 \\
General health & $57.3(21.0)$ & $49.0(21.7)$ & 0.255 \\
Vitality & $38.8(22.1)$ & $40.5(25.2)$ & 0.502 \\
Social functioning & $48.8(20.0)$ & $51.7(22.57)$ & 0.405 \\
Role emotional & $24.1(30.6)$ & $25.5(31.9)$ & 0.872 \\
Mental health & $44.6(22.6)$ & $46.4(24.7)$ & 0.968 \\
\hline
\end{tabular}

CG, control group; EG, experimental group; BMI, body mass index; SF-36, short form 36; VAS, visual analogue scale; WOMAC, Western Ontario and McMaster Universities questionnaire.

groups were found with regard to the WOMAC questionnaire or the role physical, mental health, vitality, general health, role emotional and social functioning domains of the SF-36 questionnaire (table 2).

Both groups behaved similarly over time regarding the parameters assessed during gait without the cane, with no statistically significant differences between groups (table 3). The distance covered on the 6MWT with the cane increased significantly in the EG over time in comparison with the CG $(p<0.001)$. At the end of the 6MWT, participants in the EG exhibited statistically significant improvements over time regarding the Borg scale for pain $(p=0.001)$, energy expenditure (oxygen consumption $\left(\mathrm{VO}_{2}\right)$; $\mathrm{p}=0.001)$, carbon dioxide production $\left(\mathrm{VCO}_{2} ; \mathrm{p}<0.001\right)$ and metabolic equivalents (METS; $\mathrm{p}<0.001$ ) in comparison with the CG (table 3).

Table 4 shows the effect size ( $\omega$ squared) and $95 \%$ CI for all the parameters that were significantly different between groups over time (ANOVA). 
Table 2 Between-groups comparison for pain, function and general health scores on three evaluations

\begin{tabular}{|c|c|c|c|c|c|c|c|c|c|}
\hline & \multicolumn{2}{|l|}{ TO } & \multicolumn{2}{|l|}{ T30 } & \multirow{2}{*}{$\begin{array}{l}\text { Mean } \\
\text { difference }\end{array}$} & \multicolumn{2}{|l|}{ T60 } & \multirow{2}{*}{$\begin{array}{l}\text { Mean } \\
\text { difference }\end{array}$} & \multirow{2}{*}{$\begin{array}{l}\text { p Value } \\
\text { (ANOVA) }\end{array}$} \\
\hline & CG & EG & CG & EG & & CG & EG & & \\
\hline VAS for pain (range $0-10 \mathrm{~cm}$ ) & $5.48(1.23)$ & $5.63(1.02)$ & $6.05(1.35)$ & $5.28(0.92)$ & -0.77 & $5.95(1.40)$ & $3.84(1.44)$ & -2.11 & $<0.001^{*}$ \\
\hline Lequesne (0-24) & $14.59(3.6)$ & $15.7(3.3)$ & $14.6(3.37)$ & $14.28(3.53)$ & -0.32 & $1 \mathrm{~s} 5.09(3.60)$ & $12.56(3.47)$ & -2.53 & $<0.001^{*}$ \\
\hline \multicolumn{10}{|l|}{ SF-36 (0-100) } \\
\hline Physical functioning & $28.9(13.0)$ & $35.9(17.5)$ & $33.9(15.59)$ & $37.13(14.78)$ & 3.23 & $35.94(18.94)$ & $45.00(15.08)$ & 9.06 & 0.078 \\
\hline Role physical & $22.7(24.07)$ & $23.4(31.7)$ & $24.34(31.51)$ & $32.97(29.64)$ & 8.63 & $26.06(28.33)$ & $42.81(30.21)$ & 16.75 & $0.001^{*}$ \\
\hline Vitality & $38.8(22.1)$ & $40.5(25.2)$ & $41.6(22.70)$ & $46.13(20.94)$ & 4.53 & $38.59(28.40)$ & $54.09(26.28)$ & 15.5 & 0.658 \\
\hline Social functioning & $48.8(20.0)$ & $51.7(22.57)$ & $49.5(20.80)$ & $54.89(20.02)$ & 5.39 & $49.22(19.56)$ & $57.16(17.29)$ & 7.94 & 0.597 \\
\hline Role emotional & $24.1(30.6)$ & $25.5(31.9)$ & $19.3(23.90)$ & $36.71(31.62)$ & 17.41 & $24.90(29.37)$ & $42.98(29.63)$ & 18.08 & 0.893 \\
\hline Mental health & $44.6(22.6)$ & $46.4(24.7)$ & $46.1(18.42)$ & $52.00(21.82)$ & 5.9 & $51.10(20.79)$ & $58.81(19.62)$ & 7.71 & 0.568 \\
\hline Use of NSAID (pills/month), median & - & - & 25 & 19 & & 25 & 16.5 & - & - \\
\hline $\mathrm{p}$ Value (t test) & - & - & $0.010^{*}$ & & - & $<0.001^{*}$ & & - & - \\
\hline
\end{tabular}

*Statistically significant $\mathrm{p}$ value $(<0.05)$.

ANOVA, analysis of variance; BMI, body mass index; EG, experimental group; CG, control group; NSAID, non-steroidal anti-inflammatory drug; T0, baseline; T30, evaluation after 30 days; T60, evaluation after 60 days; VAS, visual analogue scale; WOMAC, Western Ontario and McMaster Universities questionnaire.

\section{Comparisons with and without cane on 6MWT Control group}

The CG covered a greater distance $(p<0.001)$ on the 6MWT when walking without the cane at T0, T30 and T60 (figure 3A). Regarding the Borg score, less pain was found at the end of the 6MWT with the cane at T0 $(p=0.03)$. The initial heart rate was higher at the beginning of the test with the cane at T30 $(p=0.029)$ and the final heart rate was always higher when the test was performed with the cane (T0 $p=0.04$; T30 $p=0.04$; T60 $\mathrm{p}=0.011)$. The final $\mathrm{VO}_{2}(\mathrm{p}<0.001), \mathrm{VCO}_{2}(\mathrm{p}<0.001)$ and METS $(p<0.001)$ were significantly higher at the end of the 6MWT with the cane; these differences were detected on all three evaluations (figure $3 \mathrm{~B}$ ).

\section{Experimental group}

The EG covered a greater distance on the 6MWT at T0 without the cane $(p<0.001)$; however, no statistically significant difference was found between the distance covered with and without the cane at T30 and T60 (figure 3C). The patients had less pain at the end of the 6MWT with the cane at T30 ( $p=0.017)$ and $\mathrm{T} 60(\mathrm{p}=0.001)$. The heart rate was higher at the beginning of the 6MWT with the cane on the three evaluations (T0 $p=0.028$; T30 $\mathrm{p}=0.015 ; \mathrm{T} 60 \mathrm{p}=0.050)$. The heart rate was higher at the end of the 6MWT with the cane only at T0 $(p=0.006)$. With the cane, the EG had significantly higher $\mathrm{VO}_{2}, \mathrm{VCO}_{2}$ and METS values $(p<0.001)$ at the end of the 6MWT at T0 and T30 (figure 3D).

\section{NSAID intake and cane use}

Fewer NSAID pills were consumed in the EG compared with the CG at T30 $(p=0.010)$ and T60 $(p<0.001)$. Average cane use in the EG was $45 \mathrm{~min} /$ day in the first month and $74 \mathrm{~min} /$ day in the second month (table 2).

\section{DISCUSSION}

The authors were surprised to discover that, despite the fact that cane use goes back as far as ancient Egypt, very few studies have been carried out on this topic. Most investigations have been cross-sectional studies and offer no comparisons of cane use with other interventions or with no intervention at all. ${ }^{11} 1216$ The present investigation is thus the first study to assess the effectiveness of this widely used gait-assistance device among patients with knee osteoarthritis.
The results demonstrate that cane use by patients with knee osteoarthritis is an ongoing process of adaptation. All patients exhibited less efficiency in the first month, as demonstrated by the shorter distance covered and greater energy expenditure on the 6MWT. However, at the end of the second month of cane use, they were able to walk with the cane approximately the same distance and with less energy expenditure than without the cane and also experienced less pain. The intragroup comparison clearly shows the behaviour of each group and reveals the adaptation process that occurred in the EG. During this adaptation process, it is of extreme importance for healthcare professionals to educate patients regarding the difficulties they will face, especially in the first month. Such education could lead to better patient adherence to using a cane.

Pain is the main complaint among patients with knee osteoarthritis and because of this it was chosen as the primary outcome of this study. While the patients in the present study initially exhibited pain similar to that found in other studies addressing the non-pharmacological treatment of osteoarthritis, ${ }^{32} 33$ some studies report higher mean values ${ }^{34}$ and others report lower mean values, ${ }^{35} 36$ which demonstrates the variability of this parameter. ${ }^{37}$ The reduction in pain in the EG was similar to that reported in other studies involving patients with knee osteoarthritis. ${ }^{34} 3638$

The patients in the present study were overweight, but other studies on knee osteoarthritis have described similar findings. ${ }^{35} 363940$ While obesity has been described as a risk factor for the development of osteoarthritis, it is not yet clear how excess weight influences the development or progression of the disease. ${ }^{41}$

The patients in this study were considered to have grades II and III in radiological evaluation, taking into account that only patients with a knee pain score ranging from 3 to 7 were included, our sample was composed of patients with moderate involvement of osteoarthritis and none of them were eligible for knee surgery.

Function was compromised, as the Lequesne scores classified the patients as having moderate to severe limitation. In the literature, lower scores are found for the population with knee osteoarthritis. ${ }^{33} 343642$ The improvement in this parameter at the end of treatment was less than that found in a previous study in which patients were treated with hyaluronate with the same 


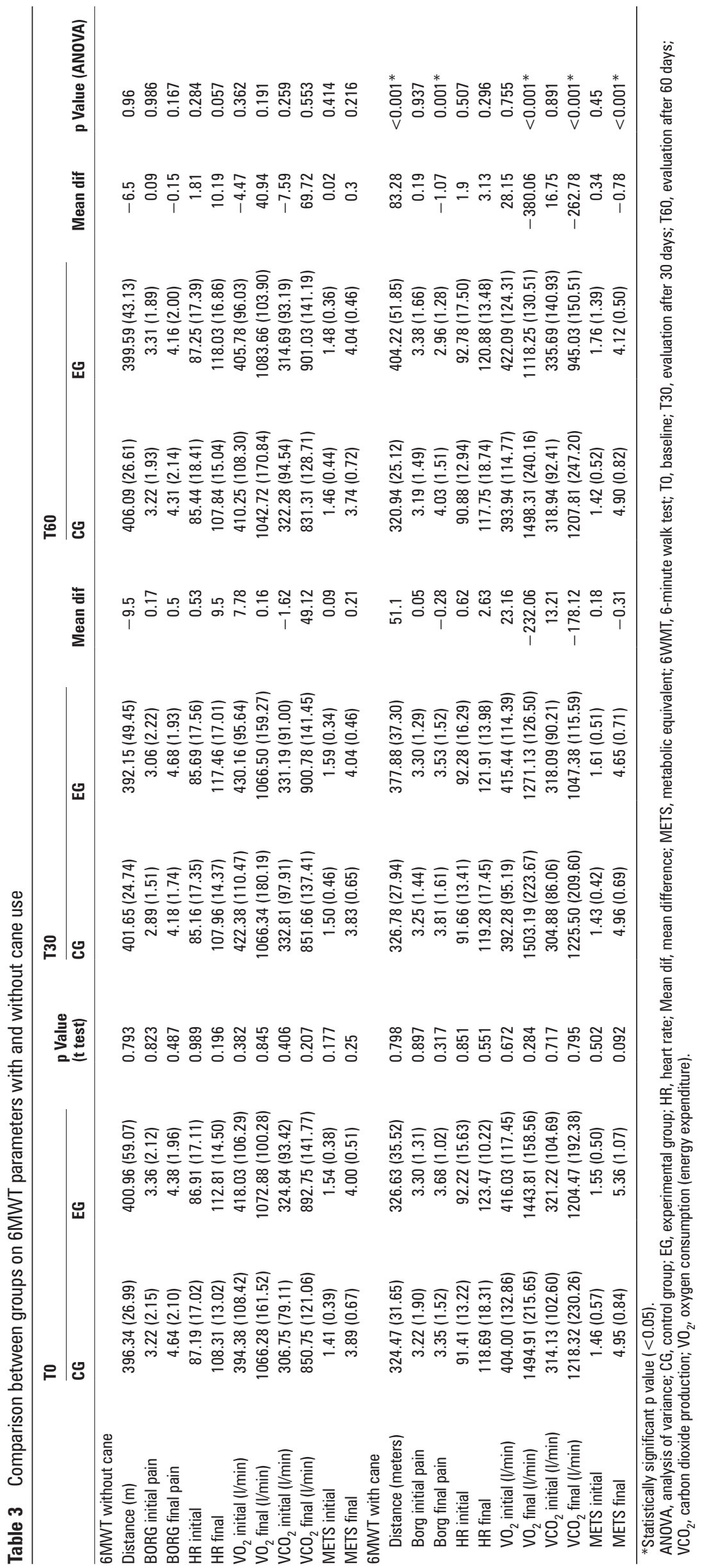




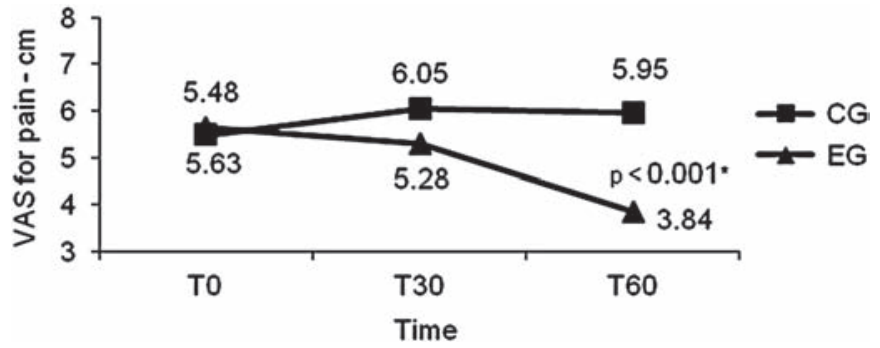

Figure 2 Differences between groups for visual analogue scale (VAS) for pain over time. CG, control group; EG, experimental group; TO, baseline; T30, evaluation after 30 days; T60, evaluation after 60 days.

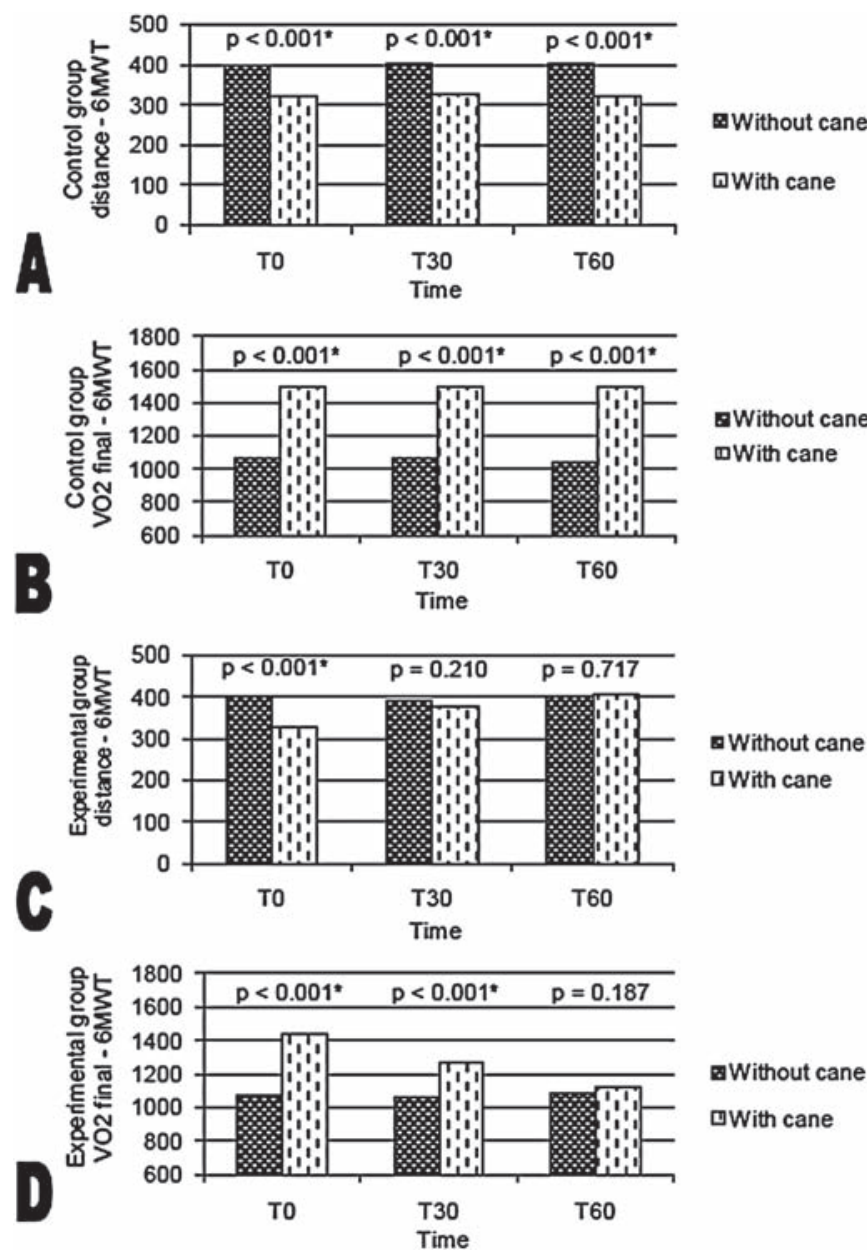

Figure 3 Comparison (paired t test) of 6-minute walk test (6MWT) parameters with cane and without cane use in control group for distance $(\mathrm{A})$ and oxygen consumption $\left(\mathrm{VO}_{2}\right)(\mathrm{B})$ and experimental group for distance (C) and $\mathrm{VO}_{2}$ (D). TO, baseline; T30, evaluation after 30 days; T60, evaluation after 60 days.

follow-up period. ${ }^{33}$ If the treatment period in the present study had been longer, it is likely that a more substantial improvement would have been achieved.

The patients in the present study exhibited considerable functional limitation, with WOMAC scores slightly higher than those described in other studies, despite the fact that the present sample was younger. ${ }^{36} 42$ Although the EG tended towards functional improvement with cane use, no significant difference was found between the groups. This may have been due to different reasons, such as the short follow-up period or chance.
Table 4 Effect size and $95 \% \mathrm{Cl}$ for the parameters that were statistically significantly different between groups with ANOVA

\begin{tabular}{ll}
\hline & ES (95\% Cl) \\
\hline Pain (VAS) & $0.18(-0.42$ to 0.87$)$ \\
Lequesne & $0.13(-0.11$ to 0.42$)$ \\
SF-36 & \\
$\quad$ Physical functioning & $0.07(-0.21$ to 0.39$)$ \\
$\quad$ Bodily pain & $0.08(-0.68$ to 1.54$)$ \\
6MWT with cane & \\
$\quad$ Distance (m) & $0.16(0.01$ to 0.69$)$ \\
Borg final pain & $0.09(0.01$ to 0.84$)$ \\
VO ${ }_{2}$ final (I/min) & $0.21(0.12$ to 0.90$)$ \\
VCO ${ }_{2}$ final (I/min) & $0.12(-0.96$ to 1.50$)$ \\
$\mathrm{METS} \mathrm{final}$ & $0.15(-0.12$ to 1.79$)$
\end{tabular}

ANOVA, analysis of variance; $E S$, effect size ( $\omega$ squared); $\omega$ squared interpretation (small 0.01, medium 0.06 and large 0.14); METS, metabolic equivalents; VAS, visual analogue scale; $\mathrm{VCO}_{2}$, carbon dioxide production; $\mathrm{VO}_{2}$, oxygen consumption (energy expenditure).

A significant improvement was found in the bodily pain and physical function subscales of the SF-36 questionnaire, which was probably related to the VAS and Lequesne findings. Studies on knee osteoarthritis describe quite varied scores in general health status following treatment, which hinders comparisons. However, the improvement in the present study was similar to that described in previous studies involving different types of treatment for patients with knee osteoarthritis. ${ }^{36} 4344$

As all patients used the same type of cane, there were no differences in this aspect that might influence the results. The choice of cane length based on the distal fold of the wrist was taken from a previous study, which had methodological flaws, but was the only study ever carried out to measure energy expenditure in patients with knee osteoarthritis. ${ }^{22}$ Moreover, care was taken to determine the angle of elbow flexion after cutting the cane in order to prevent elbow and shoulder injuries.

On the 6MWT without the cane at baseline, patients covered a distance that was less than expected for healthy adults, ${ }^{45}$ but similar to what is reported for patients with knee osteoarthritis. ${ }^{46} 47$ All patients covered similar distances at all evaluation times when walking without the cane. The patients in both groups covered a significantly shorter distance at baseline with the cane than without it. Throughout the study, however, adaptation to cane use gradually allowed the patients in the EG to walk significantly farther, until reaching a distance similar to that covered without the cane.

Cane use at baseline led to greater energy expenditure in both groups, as also demonstrated in a previous study. ${ }^{22}$ Although one previous study assessing energy expenditure during caneassisted gait in patients with knee osteoarthritis was found, ${ }^{22}$ that study assessed only the initial impact of cane use on energy expenditure, with the objective of determining whether or not cane length influenced energy expenditure in this population. The authors reported an increase in energy expenditure during cane-assisted gait, similar to that found in the baseline evaluation of the present study. ${ }^{22}$

An important finding in our study was pain following the walk test, a factor that could influence functionality. The EG patients experienced less pain at T30 and T60 when tested using the cane. This probably demonstrates adaptation to cane use, by reducing the weight load on the affected joint during gait, thereby reducing pain following the walk test.

The EG patients were asked to use the cane only outside the home. The limited amount of usage time may reflect the fact that these patients did not often leave their homes. 
Regarding NSAID intake at T30, patients in both the EG and CG groups took fewer tablets compared with patients with knee osteoarthritis in other studies. ${ }^{38} 39$ However, patients in the EG gradually reduced their NSAID intake during the study. This may reflect decreasing pain in the EG, whereas patients in the CG showed little change in the intake of pain medications. This reduction in NSAID use by the EG may be beneficial with regard to the risk of gastrointestinal and renal complications associated with the continued use of this type of medication in older patients. ${ }^{48}$

Regarding the effect size, we found a medium or large effect for all the parameters that were statistically significant with ANOVA; however, we have to view these data with caution because for some of this parameter the $95 \%$ CI included the zero value, which means that it is not statistically significant at a level of 0.05 . It is important to say that the CI represents the precision with which we are able to report the effect size, and the larger the sample, the more precise the estimate.

The results of the present study can be extrapolated to a population with knee osteoarthritis with similar characteristics to the sample of the study. It cannot be widely extrapolated to other populations with other knee problems or other degrees of severity, but it is possible that cane use would also benefit those populations. One of the limitations of the present study was the short follow-up time, considering the fact that these patients could use a cane for the rest of their lives. It is possible that a longer follow-up could lead to continued improvement. Further studies are needed to assess the impact of long-term cane use on these patients as well as its short-term and long-term impact on patients with other rheumatic conditions.

In conclusion, a cane is a gait-assistance device that can be used to diminish pain in patients with knee osteoarthritis in addition to improving function and enhancing aspects of quality of life. The prescription of a cane should take into account the substantial increase in energy expenditure in the first month of use, whereas energy expenditure is no longer a factor for concern by the end of the second month as a result of adaptation to cane use.

Funding This study was funded by grants provided by Fundacao Amparo a Pesquisa do Estado de Sao Paulo (2003/087536)

Ethics approval This study was conducted with the approval of the ethics committee of the Universidade Federal de Sao Paulo.

Patient consent Obtained.

Competing interests None.

Provenance and peer review Not commissioned; externally peer reviewed.

\section{REFERENCES}

1. Cooper C. Osteoarthritis: epidemiology and classification. In: Hochberg MC, ed Rheumatology, 3rd edn Toronto: Mosby, 2003:1782-91.

2. Miyaguchi M, Kobayashi A, Kadoya Y, et al. Biochemical change in joint fluid after isometric quadriceps exercise for patients with osteoarthritis of the knee. Osteoarthr Cartil 2003;11:252-9.

3. Fuller R, Hirose-Pastor EM. Osteoartrose. In: Yoshinari NH, Bonfá ESD, eds. Reumatologia para o Clínico, 1st edn. São Paulo: Rocca Ltda, 2000:139-48.

4. Moreira C, Carvalho MAP. Reumatologia: Diagnostico e Tratamento, 2nd edn. Rio de Janeiro: Medsi, 2001.

5. Rejeski WJ, Mihalko SL. Physical activity and quality of life in older adults. J Gerontol A Biol Sci Med Sci 2001;56:23-35.

6. Rejeski WJ, Shumaker S. Knee osteoarthritis and health-related quality of life. Med Sci Sports Exerc 1994;26:1441-5

7. Jacobson LT. Definitions of osteoarthritis in the knee and hand. Ann Rheum Dis 1996;55:656-8

8. Cailliet R. Dor no Joelho, 3rd edn. Porto Alegre: Artmed, 2001.

9. Waters RL, Mulroy S. The energy expenditure of normal and pathologic gait. Gait Posture 1999;9:207-31.

10. Schipplein OD, Andriacchi TP. Interaction between active and passive knee stabilizers during level walking. J Orthop Res 1991;9:113-19.
11. Chan GN, Smith AW, Kirtley C, et al. Changes in knee moments with contralateral versus ipsilateral cane usage in females with knee osteoarthritis. Clin Biomech (Bristol, Avon) 2005;20:396-404.

12. Joyce BM, Kirby RL. Canes, crutches and walkers. Am Fam Physician 1991:43:535-42.

13. Youdas JW, Kotajarvi BJ, Padgett DJ, et al. Partial weight-bearing gait using conventional assistive devices. Arch Phys Med Rehabil 2005;86:394-8.

14. Blount WP. Don't throw away the cane. J Bone Joint Surg Am 1956; 38-A:695-708.

15. Van der Esch M, Heijmans M, Dekker J. Factors contributing to possession and use of walking aids among persons with rheumatoid arthritis and osteoarthritis. Arthritis Rheum 2003;49:838-42.

16. Vargo MM, Robinson LR, Nicholas JJ. Contralateral v ipsilateral cane use. Effects on muscles crossing the knee joint. Am J Phys Med Rehabil 1992;71:170-6.

17. American College of Rheumatology Subcommittee on Osteoarthritis Guidelines. Recommendations for the medical management of osteoarthritis of the hip and knee: 2000 update. Arthritis Rheum 2000;43:1905-15.

18. Pendleton A, Arden N, Dougados M, et al. EULAR recommendations for the management of knee osteoarthritis: report of a task force of the Standing Committee for International Clinical Studies Including Therapeutic Trials (ESCISIT). Ann Rheum Dis 2000;59:936-44.

19. Zhang W, Moskowitz RW, Nuki G, et al. OARSI recommendations for the management of hip and knee osteoarthritis, Part II: OARSI evidence-based, expert consensus guidelines. Osteoarthr Cartil 2008;16:137-62.

20. Altman R, Asch E, Bloch D, et al. Development of criteria for the classification and reporting of osteoarthritis. Classification of osteoarthritis of the knee. Diagnostic and Therapeutic Criteria Committee of the American Rheumatism Association. Arthritis Rheum 1986;29:1039-49.

21. Kumar R, Roe MC, Scremin OU. Methods for estimating the proper length of a cane. Arch Phys Med Rehabil 1995;76:1173-5.

22. Jones A, Alves AC, de Oliveira LM, et al. Energy expenditure during cane-assisted gait in patients with knee osteoarthritis. Clinics (Sao Paulo) 2008;63:197-200.

23. Bellamy N. Osteoarthritis clinical trials: candidate variables and clinimetric properties. J Rheumato/ 1997;24:768-78.

24. Marx F, Oliveira LM, Bellini CG, et al. Tradução e validação cultural do questionário algofuncional de Lequesne para osteoartrite de joelhos e quadris para a língua portuguesa. Rev Bras Reumatol 2006;46:253-60.

25. Fernandes M. Tradução e Validação do Questionário de Qualidade de vida Específico para Osteoartrose WOMAC (Western Ontário and McMaster University) para Língua Portuguesa [tese]. São Paulo: Universidade Federal de São Paulo, 2003.

26. Ciconelli RM, Ferraz MB, Santos W, et al. Tradução para a Língua Portuguesa e Validação do Questionário Genérico de Avaliação de Qualidade de vida SF-36 (Brasil SF-36). Rev Bras Reumatol 1999;39:143-50.

27. American Thoracic Society (ATS) Committee on Proficiency Standards for Clinical Pulmonary Function Laboratories. ATS statement: guidelines for the six-minute walk test. Am J Respir Crit Care Med 2002;166:111-17.

28. Wu G, Sanderson B, Bittner V. The 6-minute walk test: how important is the learning effect? Am Heart J 2003;146:129-33.

29. Borg GA. Psychophysical bases of perceived exertion. Med Sci Sports Exerc 1982;14:377-81.

30. Filho UD. Testando hipóteses. In: Filho UD, ed. Introdução à Bioestatística para Simples Mortais, 2nd edn. Sao Paulo: Negócio Editora Ltda, 1999: 70-2.

31. Olejnik S, Algina J. Generalized eta and omega squared statistics: measures of effect size for some common research designs. Psychol Methods 2003;8:434-47.

32. Bennell KL, Hinman RS, Metcalf BR, et al. Efficacy of physiotherapy management of knee joint osteoarthritis: a randomised, double blind, placebo controlled trial. Ann Rheum Dis 2005;64:906-12.

33. Sun SF, Hsu CW, Hwang CW, et al. Hyaluronate improves pain, physical function and balance in the geriatric osteoarthritic knee: a 6-month follow-up study using clinical tests. Osteoarthr Cartil 2006;14:696-701.

34. Atamaz F, Kirazli Y, Akkoc Y. A comparison of two different intra-articular hyaluronan drugs and physical therapy in the management of knee osteoarthritis. Rheumatol Int 2006;26:873-8.

35. Smith MD, Wetherall M, Darby T, et al. A randomized placebo-controlled trial of arthroscopic lavage versus lavage plus intra-articular corticosteroids in the management of symptomatic osteoarthritis of the knee. Rheumatology (Oxford) 2003:42:1477-85.

36. Eyigor S, Hepguler S, Capaci K. A comparison of muscle training methods in patients with knee osteoarthritis. Clin Rheumatol 2004;23:109-15.

37. Paradowski PT, Englund M, Lohmander LS, et al. The effect of patient characteristics on variability in pain and function over two years in early knee osteoarthritis. Health Qual Life Outcomes 2005;3:59.

38. Silva LE, Valim V, Pessanha AP, et al. Hydrotherapy versus conventional land-based exercise for the management of patients with osteoarthritis of the knee: a randomized clinical trial. Phys Ther 2008;88:12-21.

39. Hay EM, Foster NE, Thomas E, et al. Effectiveness of community physiotherapy and enhanced pharmacy review for knee pain in people aged over 55 presenting to primary care: pragmatic randomised trial. BMJ 2006;333:995. 
40. Jinks C, Jordan K, Croft P. Disabling knee pain-another consequence of obesity: results from a prospective cohort study. BMC Public Health 2006;6:258.

41. Powell A, Teichtahl AJ, Wluka AE, et al. Obesity: a preventable risk factor for large joint osteoarthritis which may act through biomechanical factors. Br J Sports Med 2005;39:4-5.

42. Herrero-Beaumont G, Ivorra JA, Del Carmen Trabado M, et al. Glucosamine sulfate in the treatment of knee osteoarthritis symptoms: a randomized, double-blind, placebo-controlled study using acetaminophen as a side comparator. Arthritis Rheum 2007;56:555-67.

43. Beaupre LA, Lier D, Davies DM, et al. The effect of a preoperative exercise and education program on functional recovery, health related quality of life, and health service utilization following primary total knee arthroplasty. J Rheumatol 2004;31:1166-73.

44. Nuñez M, Nuñez E, Segur JM, et al. The effect of an educational program to improve health-related quality of life in patients with osteoarthritis on waiting list for total knee replacement: a randomized study. Osteoarthr Cartil 2006;14:279-85.
45. Bautmans I, Lambert M, Mets T. The six-minute walk test in community dwelling elderly: influence of health status. BMC Geriatrics 2004;23:4-6.

46. Deyle GD, Henderson NE, Matekel RL, et al. Effectiveness of manual physical therapy and exercise in osteoarthritis of the knee. A randomized, controlled trial. Ann Intern Med 2000;132:173-81.

47. Messier SP, Mihalko S, Loeser RF, et al. Glucosamine/chondroitin combined with exercise for the treatment of knee osteoarthritis: a preliminary study. Osteoarthr Cartil 2007:15:1256-66.

48. Mazières B, Bannwarth B, Dougados $\mathrm{M}$, et al. EULAR recommendations for the management of knee osteoarthritis. Report of a task force of the Standing Committee for International Clinical Studies Including Therapeutic Trials. Joint Bone Spine 2001;68:231-40 